\title{
Impairment of motor planning in patients with Parkinson's disease: evidence from ideomotor apraxia testing
}

\author{
G GOLDENBERG, A WIMMER, E AUFF, G SCHNABERTH \\ From Neurologische Universitätsklinik, Wien, Austria
}

\begin{abstract}
SUMMARY Compared with a group of age matched controls, patients with Parkinson's disease scored significantly lower in testing for ideomotor apraxia. Imitation of movement sequences was affected more severely than performance of single movements. The degree of impairment was not related to severity of motor disability, but correlated strongly with the results of tests that measured visuospatial and visuoperceptive abilities. It is suggested that defective encoding and central processing of visuospatial information impairs memory for movement which is necessary for correct imitation of movements. Enhanced vulnerability to interference between successively presented items may cause further deterioration of performance in the copying of movement sequences.
\end{abstract}

Ideomotor apraxia has been defined as a failure to produce either a correct movement on verbal command or to imitate correctly a movement performed by the examiner when the incorrect performance cannot be explained by weakness, incoordination, akinesia, abnormal reflexes, impaired auditory comprehension, or impaired visual or tactile perception. ${ }^{1}$ This had led to the conclusion that ideomotor apraxia is an inaccurate term to associate with Parkinson's disease because the patients manifest motor deficits. ${ }^{2}$

With regard to the examination of motor behaviour the distinction between apraxic errors and lower level deficits of motor control has been expressed as follows: "The diagnosis of ideomotor apraxia is not made if a patient fails to carry out certain movements at all, nor is mere clumsiness of movement sufficient to consider a patient apraxic. The diagnosis is made when a patient is impaired in the proper selection of the motor elements which constitute a movement and in the correct ordering of these elements in a motor sequence". ${ }^{3}$ Errors that fit into this definition have been observed in patients with Parkinson's disease and seem to indicate a deficit in central motor planning. ${ }^{24-6}$ The aim of the present study was to find out whether such a deficit would show up in con-

Address for reprint requests: Dr G Goldenberg, Neurologische Universitätsklinik, Lazarettgasse 14, A 1090 Wien, Austria.

Received 4 June 1985 and in revised form 18 November 1985. Accepted 23 November 1985 ventional testing of ideomotor apraxia and to look into the relationship between apraxia scores and motor disability, visuospatial deficits, and general intellectual deterioration. Instead of discussing whether the demonstrated impairment in apraxia testing warrants a diagnosis of ideomotor apraxia, we thought that a more interesting question would be whether concomitant basal ganglia damage might be a contributing factor to ideomotor apraxia in patients with left hemisphere lesions affecting the cortex and the fibre systems connecting cortical areas.

\section{Subjects}

Forty two patients (17 female, 25 male) with idiopathic Parkinson's disease were examined. Twenty eight of them were out-patients, 14 were examined during hospitalisation for therapeutic reasons. Motor symptoms were bilateral in all cases, and their distribution was symmetric in 23 . In 15 patients the right side of the body was more severely affected and four patients showed greater impairment on the left. All patients had at least some degree of bradykinesia, rigor, and gait disturbance, and tremor was conspicuous in 26 of them. Mean duration of illness was 8.95 years, and 14 patients had had symptoms for more than 10 years. Motor disability (see below) was rated mild for seven patients, medium for 18 , and severe for 17 , but no patient was confined to wheelchair or bed during the period of examination. All patients were treated with levodopa and benseracid; 18 of them also received anticholinergic drugs.

The control group consisted of 38 neurological patients (18 female, 20 male) who suffered from disease of the muscles, the peripheral nerves, or the spinal cord; none of 
them showed evidence of cerebral damage. Fifteen were outpatients and 23 were hospitalised during the period of examination.

\section{Methods}

Motor disability was rated by one of the authors who was not aware of the results of the neuropsychological examinations. According to the criteria proposed by Birkmayer and Neumayer, ${ }^{78}$ patients were grouped for mild, medium, and severe disability. ${ }^{8}$ Evaluation with this scale considers impairment in starting, walking, balance, posture, writing, speech, and facial expression. As a rough guide, a patient classified as "mildly impaired" falls within stage 1 or 2 of the Hoehn and Yahr scale, and a severe impairment corresponds to stages 4 and 5 of this scale.

Neuropsychological examinations were administered during two sessions within one week. The test battery was chosen to measure general intellectual deterioration and dementia, visuospatial abilities, and ideomotor apraxia:

Memory was examined by free recall of a list of 12 unrelated concrete nouns and a list of 12 two-digit numbers. The score was the number of items correctly recalled after one presentation. Vocabulary was assessed by the Boston Naming Test $(\mathrm{BNT})^{10}$ which had been revised for use with German speaking subjects. The WAIS subtest picture completion was administered and evaluated in the usual way. The Rorschach test was given, and signs of organic brain syndrome were rated on a 4-point scale according to the criteria proposed by Piotrowsky. ${ }^{11}$ Critical flicker fusion was measured as an index of vigilance and concentration. Visuospatial abilities were evaluated by four tests: (1) Judgement of line orientation was scored without the proposed corrections for age, sex and educational level. ${ }^{12}$ This test demands the estimation of the directions of two lines by comparison with a set of 11 angles. (2) Ratcliff's mannekin test of mental rotation, ${ }^{13}$ which requires the distinction between the right and the left side of a human figure seen in different positions, was extended to include profile views of the mannekin in addition to frontal and dorsal views. The score was the number of correct responses for all positions, but subjects were asked to correct when they committed errors for the upright-dorsal position. (3) Assembly of geometric figures required the patient to copy geometric line patterns by means of four to six quadratic plates, each having either an oblique or a straight line on it. The maximum score of each item was half the number of plates involved. If the patient committed errors but corrected after comparison with the model, one point was subtracted; in case of persistent error no point was given. (4) The WAIS subtest figure assembly was administered without time limits, and neither Parkinson's disease patients nor controls received additional points for quick performance. In both assembly tests inaccuracy caused by temor was neglected for scoring.

In apraxia testing the patient was free to choose the preferred hand. There were four imitation items: six finger postures, each involving two or three fingers (for example form a ring with thumb and small finger; extend the thumb, the index and the small finger); six positions of the hand (for example hold the hand vertically under the chin with the ulnar side looking forwards; ${ }^{14}$ touch the contralateral cheek with the back of the hand); six movement sequences which required different combinations of simultaneous movements of arm, hand and fingers (for example touch the upper arm with the ulnar edge of the hand, then touch the forearm with the same ulnar edge, then touch the upper arm with the palm ${ }^{15}$ make a fist beside the head, then extend the arm and form a ring with thumb and middle finger; ${ }^{14}$ point with the index to the ipsilateral eye, then place the palm upon the contralateral shoulder); and a sequence of finger tapping (opposing once the index, twice the middle finger, once the ring finger, twice the small finger to the thumb) which was demonstrated simultaneously to counting the number of tappings out loud. In all imitation items the patient was allowed to start performance only after the examiner had terminated the demonstration. Two points were given for a correct performance. In case of failure, demonstration was repeated and one point was credited for a correct performance on second trial. The finger tapping sequence was demonstrated in up to three trials and hence a maximum of three points could be obtained.

Six symbolic gestures and six pantomimes of object use were examined on verbal command only. Again, correct performance on first trial yielded two points. In case of failure the meaning of the gesture or the demand to pantomime the use of an implement was reexplained, and one point was credited for a correct second trial. Generally, slowness of execution and disturbance of movement by tremor or reduced motility were not considered as failures. The prevailing types of errors were the same in Parkinsonians and controls: confusion of fingers in imitation of finger postures; spatial errors in imitation of hand positions and of whole limb movement sequences, frequently occurring already with the first movement of a sequence; omission of tapping with the fourth and fifth finger and loss of the 1-1, 2-1-1, 2 rhythm in the finger tapping sequence; omission or incorrect patterns of movement of single digits in symbolic gestures, and body part as object errors in pantomine of object use.

\section{Statistical analysis}

Rating of organic brain syndrome and of motor disability obviously operated on an ordinal scale level. The interval scale level of some of the other subtests could be disputed, because rating was based on a combination of different criteria. For example, scoring combined the number of correct items with an evaluation of whether a task was achieved with or without correction. Therefore, nonparametric statistics based on rankings were choosen to determine the significance level of differences and to estimate the strength of correlations. Because multiple comparisons and correlations were being computed for the same data set a probability of 0.001 was considered to be a maximum for interpreting a single result as being significant. In interpreting partial correlations, however, a 0.01 level of significance was accepted since this procedure controls more strictly for common influences of nonspecific factors.

\section{Results}

Within each group scores of finger and hand positions as well as of geometric figure and WAIS figure assembly showed no significant differences (Wilcoxon test for iepeated measures, $p>0 \cdot 20$ ). They were col- 
Table 1 Comparison between groups

\begin{tabular}{|c|c|c|c|c|c|}
\hline & \multicolumn{2}{|c|}{ Parkinsonian patients } & \multicolumn{2}{|c|}{ Controls } & \multirow{2}{*}{$\begin{array}{l}p \text { (Mann-Whitney } \\
\text { U-test) }\end{array}$} \\
\hline & Mean & Range & Mean & Range & \\
\hline $\begin{array}{l}\text { Age } \\
\text { Memory } \\
\text { Organic brain syndrome } \\
\text { Picture completion } \\
\text { Vocabulary (BNT) } \\
\text { Flicker fusion } \\
\text { Line orientation } \\
\text { Mental rotation } \\
\text { Figure assembly } \\
\text { Finger and hand positions } \\
\text { Finger tapping sequence } \\
\text { Movement sequences } \\
\text { Symbolic gestures } \\
\text { Pantomime of object use } \\
\text { Apraxia score }\end{array}$ & $\begin{array}{r}67,6 \\
7,6 \\
1,3 \\
9,3 \\
49,6 \\
36,0 \\
17,8 \\
28,0 \\
23,3 \\
19,8 \\
1,6 \\
7,6 \\
11,5 \\
9,4 \\
49,2\end{array}$ & $\begin{array}{c}35-83 \\
0-15 \\
0-3 \\
1-14 \\
22-60 \\
29-42 \\
0-30 \\
14-31 \\
1-35 \\
11-24 \\
0-3 \\
1-12 \\
8-12 \\
0-12 \\
20-62\end{array}$ & $\begin{array}{r}66,3 \\
9,1 \\
0,9 \\
10,2 \\
52,2 \\
37,1 \\
21,3 \\
29,1 \\
28,8 \\
21,4 \\
2,4 \\
9,7 \\
11,8 \\
10,0 \\
55,0\end{array}$ & $\begin{array}{l}41-86 \\
4-18 \\
0-3 \\
6-15 \\
40-60 \\
33-42,5 \\
11-29 \\
20-32 \\
11-35 \\
16-24 \\
0-3 \\
4-12 \\
10-12 \\
5-12 \\
44-62\end{array}$ & $\begin{array}{l}0.47 \\
0.10 \\
0.089 \\
0.29 \\
0.28 \\
0.064 \\
0.046 \\
0.64 \\
0.0095 \\
0.039 \\
0.0051 \\
0.0001 \\
0.32 \\
0.48 \\
0.0003\end{array}$ \\
\hline
\end{tabular}

lapsed to "figure assembly" and "finger and hand positions" respectively.

\section{Comparison between groups}

The mean results of Parkinson's disease patients were worse than those of controls in all tests, but the differences reached the 0.001 level of significance only in whole limb movement sequences and the total apraxia score (table 1).

Correlation within groups

Only in the control group did females score significantly lower than males in WAIS picture completion $(p=0.0012)$, and judgement of line orientation $(p=0.0012)$. In the patient group there were no significant correlations between test scores and duration of illness, nor were there any significant differences pertaining to lateralisation of motor symptoms, presence of marked tremor, or medication with anticholinergic drugs.

In both groups there were significant correlations between picture completion and the BNT on the one hand and tests of visuospatial abilities on the other (table 2). These correlations were somewhat stronger

Table 2 Relationship of visuospatial abilities to age, motor symptoms, and intellectual decline

\begin{tabular}{lccc}
\hline & Line orientation & Mental rotation & Figure assembly \\
\hline & & Parkinsonian patients & -0.17 \\
Age & -0.32 & -0.19 & -0.40 \\
Motor disability & -0.45 & $0.54^{*}$ & -0.44 \\
Memory & 0.42 & -0.49 & $0.48^{*}$ \\
Organic brain syndrome & -0.36 & 0.39 & 0.28 \\
Picture completion & $0.59^{*}$ & 0.39 & $0.70 \ddagger$ \\
Vocabulary (BNT) & $0.54^{*}$ & $9 \cdot 16$ & 0.33 \\
Flicker fusion & 0.27 & Controls & \\
& & -0.30 & 0.35 \\
Age & -0.34 & -0.13 & 0.25 \\
Memory & 0.046 & $0.57^{*}$ & -0.080 \\
Organic brain syndrome & -0.0070 & 0.059 & $0.57^{*}$ \\
Picture completion & 0.46 & 0.30 & $0.54^{*}$ \\
Vocabulary (BNT) & 0.41 & 0.40 \\
Flicker fusion & 0.37 &
\end{tabular}

Spearman correlation coefficients; ${ }^{*} \mathrm{p}<0.001,+\mathrm{p}<0.0001, \ddagger \mathrm{p}<0.00001$.

Table 3 Relationship of general intellectual decline to age and motor symptoms

\begin{tabular}{|c|c|c|c|c|c|}
\hline & Memory & $\begin{array}{l}\text { Organic brain } \\
\text { syndrome }\end{array}$ & Picture completion & $\begin{array}{l}\text { Vocabulary (Picture } \\
\text { naming) }\end{array}$ & Flicker fusion \\
\hline \multicolumn{6}{|c|}{ Parkinsonian patients } \\
\hline Age & $-0.49^{*}$ & 0.14 & -0.31 & $-0 \cdot 18$ & $-0.63 t$ \\
\hline
\end{tabular}

Spearmen correlation coefficients; ${ }^{*} p<0.001$, tp $<0.0001$. 
Table 4 Relationship of Apraxia scores to age, motor symptoms and intellectual decline

\begin{tabular}{|c|c|c|c|c|c|c|}
\hline & $\begin{array}{l}\text { Finger \& hand } \\
\text { positions }\end{array}$ & $\begin{array}{l}\text { Finger tapping } \\
\text { sequence }\end{array}$ & $\begin{array}{l}\text { Movement } \\
\text { sequence }\end{array}$ & $\begin{array}{l}\text { Symbolic } \\
\text { gestures }\end{array}$ & $\begin{array}{l}\text { Pantomime of } \\
\text { object use }\end{array}$ & Apraxia score \\
\hline \multicolumn{7}{|c|}{ Parkinsonian patients } \\
\hline Age & -0.16 & -0.33 & $-0 \cdot 19$ & -0.033 & -0.21 & -0.36 \\
\hline Motor disability & -0.27 & -0.36 & -0.21 & -0.24 & -0.12 & -0.32 \\
\hline Memory & 0.37 & $0.55^{*}$ & 0.23 & 0.013 & 0.17 & 0.46 \\
\hline \multicolumn{7}{|l|}{ Psychoorganic } \\
\hline syndrome & 0.23 & 0.40 & $0 \cdot 14$ & $0 \cdot 12$ & $0 \cdot 13$ & 0.32 \\
\hline Picture completion & $0.48^{*}$ & $0.50^{*}$ & 0.21 & 0.32 & 0.22 & $0.51 *$ \\
\hline Vocabulary (BNT) & $0.48^{*}$ & $0.50^{*}$ & 0.39 & 0.17 & 0.45 & $0.50^{*}$ \\
\hline \multirow[t]{2}{*}{ Flicker fusion } & 0.22 & 0.23 & 0.22 & $0 \cdot 17$ & 0.35 & 0.31 \\
\hline & \multicolumn{6}{|c|}{ Controls } \\
\hline Age & -0.16 & $-0 \cdot 16$ & -0.37 & -0.30 & -0.21 & -0.29 \\
\hline Memory & 0.30 & 0.053 & $0.54^{*}$ & 0.085 & 0.42 & $0.54^{*}$ \\
\hline \multicolumn{7}{|l|}{ Psychoorganic } \\
\hline syndrome & $0 \cdot 23$ & 0.012 & 0.099 & $0 \cdot 32$ & 0.17 & 0.080 \\
\hline Picture completion & $0.40^{*}$ & 0.37 & $0.59^{*}$ & 0.045 & 0.26 & $0.58^{*}$ \\
\hline Vocabulary (BNT) & 0.31 & 0.33 & 0.37 & 0.078 & 0.23 & $0.51 *$ \\
\hline Flicker fusion & $0 \cdot 15$ & 0.11 & 0.48 & 0.33 & 0.24 & $0 \cdot 30$ \\
\hline
\end{tabular}

Spearman correlation coefficients; ${ }^{*} \mathrm{p}<0.001$.

Table 5 Relationship between Apraxia scores and visuospatial abilities

\begin{tabular}{|c|c|c|c|c|c|c|}
\hline & $\begin{array}{l}\text { Finger \& hand } \\
\text { positions }\end{array}$ & $\begin{array}{l}\text { Finger tapping } \\
\text { sequence }\end{array}$ & $\begin{array}{l}\text { Movement } \\
\text { sequence }\end{array}$ & $\begin{array}{l}\text { Symbolic } \\
\text { gestures }\end{array}$ & $\begin{array}{l}\text { Pantomime of } \\
\text { object use }\end{array}$ & Apraxia score \\
\hline \multirow{7}{*}{$\begin{array}{l}\text { Line orientation } \\
\text { Controlling for Age } \\
\text { Memory } \\
\text { Picture completion } \\
\text { Vocabulary (BNT) } \\
\text { Age, memory, picture completion } \\
\text { and vocabulary }\end{array}$} & & Par & sonian patient & & & \\
\hline & 0.64 & $0.39 *$ & $0.49^{*}$ & $0 \cdot 27$ & $0.47^{*}$ & $0.62 t$ \\
\hline & 0.63 & 0.32 & $0.46^{*}$ & 0.29 & $0.43^{*}$ & $0.56 t$ \\
\hline & $0.57^{* *}$ & $0 \cdot 22$ & $0.45^{*}$ & 0.30 & $0.45^{*}$ & $0.52 t$ \\
\hline & $0.51^{* *}$ & 0.14 & $0.46^{*}$ & 0.10 & $0.43^{*}$ & $0.45^{*}$ \\
\hline & $0.51^{* *}$ & $0 \cdot 16$ & $0 \cdot 36$ & $0 \cdot 21$ & $0 \cdot 30$ & $0.47^{*}$ \\
\hline & $0 \cdot 45^{*}$ & -0.057 & $0.40^{*}$ & $0 \cdot 16$ & 0.37 & 0.35 \\
\hline \multirow{6}{*}{$\begin{array}{l}\text { Mental rotation } \\
\text { Controlling for Age } \\
\text { Memory } \\
\text { Picture completion } \\
\text { Vocabulary (BNT) } \\
\text { Age, memory, picture completion } \\
\text { and vocabulary }\end{array}$} & $0.52 t$ & $0.48^{*}$ & $0.42^{*}$ & 0.23 & $0.47^{*}$ & $0.62 \ddagger$ \\
\hline & $0.51^{*}$ & $0.46^{*}$ & $0.40^{*}$ & 0.24 & 0.12 & $0.54 \uparrow$ \\
\hline & $0.42 *$ & 0.27 & 0.36 & $0 \cdot 28$ & 0.071 & $0.41^{*}$ \\
\hline & $0.42^{*}$ & 0.36 & $0.37^{*}$ & 0.12 & 0.068 & $0.45^{*}$ \\
\hline & $0.42^{*}$ & 0.36 & $0 \cdot 31$ & 0.18 & -0.034 & $0.45^{*}$ \\
\hline & 0.34 & $0 \cdot 18$ & 0.33 & $0 \cdot 20$ & -0.0059 & 0.35 \\
\hline \multirow{5}{*}{$\begin{array}{l}\text { Figure assembly } \\
\text { Controlling for Age } \\
\text { Memory } \\
\text { Picture completion } \\
\text { Vocabulary (BNT) } \\
\text { Age, memory, picture completion } \\
\text { and vocabulary }\end{array}$} & $0.68 t$ & $0.64 \ddagger$ & $0.48^{*}$ & 0.31 & $0.43^{*}$ & $0.72 \ddagger$ \\
\hline & $0.68 t$ & $0.59 \ddagger$ & $0.44^{*}$ & 0.35 & $0.38^{*}$ & $0.67 \pm$ \\
\hline & $0.62 \ddagger$ & $0.52 \dagger$ & $0.43^{*}$ & 0.36 & $0.40^{*}$ & $0.64 t$ \\
\hline & $\begin{array}{l}0.54 \dagger \\
0.54 \dagger\end{array}$ & $\begin{array}{l}0.48^{*} \\
0.48^{*}\end{array}$ & $\begin{array}{l}0.47^{*} \\
0.31\end{array}$ & $\begin{array}{l}0.14 \\
0.28\end{array}$ & $\begin{array}{l}0.39^{*} \\
0.17\end{array}$ & $\begin{array}{l}0.59 t \\
0.60 t\end{array}$ \\
\hline & $0.48^{*}$ & 0.32 & $0.37^{*}$ & 0.22 & 0.25 & $0.48^{*}$ \\
\hline \multirow{7}{*}{$\begin{array}{l}\text { Line orientation } \\
\text { Controlling for Age } \\
\text { Memory } \\
\text { Picture completion } \\
\text { Vocabulary (BNT) } \\
\text { Age, memory, picture completion } \\
\text { and vocabulary }\end{array}$} & & & Controls & & & \\
\hline & $0 \cdot 14$ & 0.093 & 0.34 & -0.083 & 0.37 & 0.28 \\
\hline & 0.095 & 0.041 & 0.24 & 0.018 & 0.32 & 0.20 \\
\hline & 0.14 & 0.090 & 0.37 & -0.088 & $0.39 *$ & 0.30 \\
\hline & -0.054 & -0.095 & 0.90 & -0.12 & $0 \cdot 29$ & 0.012 \\
\hline & 0.016 & -0.049 & 0.22 & -0.13 & 0.31 & 0.087 \\
\hline & -0.50 & $-0 \cdot 22$ & $0 \cdot 15$ & 0.017 & $0.40 *$ & 0.043 \\
\hline \multirow{5}{*}{$\begin{array}{l}\text { Mental rotation } \\
\text { Controlling for Age } \\
\text { Memory } \\
\text { Picture completion } \\
\text { Vocabulary (BNT) } \\
\text { Age, memory, picture completion } \\
\text { and vocabulary }\end{array}$} & 0.088 & $0 \cdot 25$ & $0.52 \dagger$ & 0.046 & -0.018 & $0 \cdot 20$ \\
\hline & 0.041 & $0 \cdot 21$ & $0.46^{*}$ & 0.15 & -0.089 & 0.12 \\
\hline & -0.018 & 0.25 & $0.42^{*}$ & $\begin{array}{r}0.017 \\
0.024\end{array}$ & -0.19 & $\begin{array}{l}0.013 \\
0.19\end{array}$ \\
\hline & $\begin{array}{r}-0.19 \\
0.073\end{array}$ & $\begin{array}{l}0.052 \\
0.24\end{array}$ & $\begin{array}{l}0.29 \\
0.54 \dagger\end{array}$ & $\begin{array}{l}0.024 \\
0.04\end{array}$ & $\begin{array}{l}-0.21 \\
-0.032\end{array}$ & $\begin{array}{r}-0.19 \\
0.20\end{array}$ \\
\hline & -0.20 & $0 \cdot 15$ & 0.26 & 0.078 & -0.29 & -0.22 \\
\hline \multirow{6}{*}{$\begin{array}{l}\text { Figure assembly } \\
\text { Controlling for Age } \\
\text { Memory } \\
\text { Picture completion } \\
\text { Vocabulary (BNT) } \\
\text { Age, memory, picture completion } \\
\text { and vocabulary }\end{array}$} & 0.25 & 0.30 & $0.47^{*}$ & 0.050 & 0.16 & $0.43^{*}$ \\
\hline & $0 \cdot 21$ & 0.26 & $0.40^{*}$ & 0.17 & 0.094 & 0.37 \\
\hline & 0.19 & 0.29 & $0.41^{*}$ & 0.030 & 0.059 & 0.37 \\
\hline & $\begin{array}{l}0.026 \\
0 \cdot 10\end{array}$ & $\begin{array}{l}0.11 \\
0.15\end{array}$ & $\begin{array}{l}0.21 \\
0.35\end{array}$ & $\begin{array}{l}0.030 \\
0.97\end{array}$ & $\begin{array}{l}0.012 \\
0.041\end{array}$ & $\begin{array}{l}0.15 \\
0.22\end{array}$ \\
\hline & & & & & & \\
\hline & -0.012 & 0.034 & $0 \cdot 20$ & 0.11 & -0.029 & 0.080 \\
\hline
\end{tabular}

Partial correlations computed from correlation matrix of Spearman correlation coefficients; ${ }^{*} p<0.01, \dagger p<0.001, \ddagger p<0.0001$. 
in the Parkinson's disease group, and only in Parkinson's disease patients did the relationship between memory and visuospatial tests reach significance as well. Most likely these results indicate an influence of general intellectual decline on visuospatial abilities.

In Parkinson's disease only picture completion showed a significant correlation to motor disability (table 3), but the respective correlations of line orientation and figure assembly were close to the chosen significance level (table 2). Picture completion requires the evaluation of line drawings and may be sensitive to visuoperceptive impairment. The correlations may thus be interpreted as being a partial confirmation of previous findings of a progressive decline of visuospatial and visuoperceptive abilities with advancing stages of motor disability. ${ }^{16-19}$

The impairment of Parkinson's disease patients in apraxia testing showed no significant correlation with the disability score (table 4). In both, Parkinsonians and controls, there were significant correlations between verbal memory, picture completion and the BNT on the one hand, and apraxia scores on the other. General intellectual decline seems to have a deleterious influence on performance in apraxia testing.

In Parkinson's disease patients all visuospatial tests correlated strongly with the total apraxia score and with finger and hand positions, and figure assembly showed a significant correlation with the finger tapping sequence as well. In contrast, in controls only the correlation between mental rotation and the whole limb movement sequence reached significance (table 5).

The correlation between visuospatial tests and apraxia scores could have been simulated by a common influence of general intellectual deterioration or age upon both kinds of measures. Therefore, partial correlations were calculated controlling for the respective items and for their possible combinations (table 5). In both groups, a decrease of more than $0 \cdot 1$ in at least one correlation coefficient was obtained by controlling for age, memory, picture completion, and the BNT respectively. Control for motor disability did not affect correlation coefficients in Parkinsonians and control for the results of the Rorschach test and for critical flicker fusion had no distinct effect in either group. In both groups control for the combination of memory, picture completion, the BNT, and age turned out to be most effective in lowering the strength of correlations between visuospatial tests and apraxia scores: In the control group the correlations with the total apraxia score fell to values about zero, and only the correlation between judgement of line orientation and pantomime of object use maintained significance.

In contrast, in the Parkinson's disease group a 0.01 level of significance was maintained in the relationship of figure assembly to the total apraxia score, to finger and hand positions, and to movement sequences, as well as in the correlations of line orientation to finger and hand positions and to movement sequences. The correlations between mental rotation and apraxia scores lost significance. Apparently the relationship between visuospatial abilities and apraxia scores pertains to the exact perception of complex visuospatial information rather than to "spatial thinking". ${ }^{13}$ However, this relationship appears to be in part independent of intellectual deterioration and age.

\section{Discussion}

In testing for apraxia we took great care to consider only failures that could not be ascribed to akinesia, hypomotility or tremor, and there was no difference in the types of errors committed by patients with Parkinson's disease and by controls. Whereas picture completion which requires no motor responses showed a significant correlation with the disability score, scores in apraxia testing did not. Therefore, the demonstrated impairment in apraxia testing cannot be convincingly explained as being a sequel of insufficient motor execution due to akinesia, hypomotility, or tremor.

With the exception of a few hand positions which required placing of the hand under the chin or beside the head, all movements could be monitored visually by the subject himself, and there were no time constraints on performance. It thus seems improbable that the impairment of Parkinson's disease patients was due to the deficit in "open loop" control of voluntary movements that has been repeatedly described as a sequel of basal ganglia damage. ${ }^{4620}$

The mean scores of Parkinson's disease patients were lower than those of controls in all tests presumed to assess general intellectual deterioration and dementia, but these differences did not reach statistical significance. Keeping in mind that significant declines of memory and vocabulary are already found in mild dementia of the Alzheimer type, ${ }^{21}$ one cannot reasonably consider the impairment in apraxia testing of our Parkinson's disease patients as being a symptom of concomitant dementia of the Alzheimer type.

Whether the failure in apraxia testing could be conceived of as being a sequel of defective visuospatial perception seems to be a more difficult question to answer: in accordance with the findings of Shape $e t$ $a l^{28}$ we found Parkinson's disease patients to be significantly worse than controls in imitation of movements but not in performance of movements on verbal command. Apraxia scores of Parkinson's disease patients showed strong correlations to the results 
of tests that measured visuospatial abilities but did not require a skilled motor response. From these findings it could be presumed that defective imitation of movement resulted from defective perception of the exact spatial features of the demonstated movement. We think, however, that another possible relation between visuospatial deficit and impaired imitation of movement should be considered: patients were allowed to start performance only after demonstration was terminated. Thus, short term memory for movement intervened between perception and performance. When movements are to be memorised they are encoded in terms of their visuospatial features rather than in patterns of motor innervation. ${ }^{22}$ Consequently, if there is a deficit in central processing of visuospatial information it should affect memory for movements. A deficit in memory for movement could account for the greater impairment in imitating movement sequences than in imitating single movements, because the total amount of information that has to be stored to memorise a movement sequence is obviously greater than that necessary to memorise a single movement.

Increased sensitivity to interference between successive components of the movement sequences might have added to the deleterious effect of impaired visuospatial encoding on memory for movements in patients with Parkinson's disease. The basal ganglia function in close interaction with the frontal lobes, ${ }^{623}$ and there is evidence that patients with even mild Parkinson's disease exhibit psychological deficits which resemble those of patients with frontal lobe damage. ${ }^{24-26}$ Increased vulnerability to interference between successively presented items of memory tasks has been documented in human patients and in animals with frontal lobe damage. ${ }^{142728}$

Considering the correlations between the verbal memory task and apraxia subtests one notes a great difference between Parkinsonians and controls with regard to the finger tapping sequence: in Parkinsonians there was a significant correlation between memory and finger tapping, whereas in controls there was hardly any correlation at all. The amount of information that has to be memorised for repeating the finger tapping sequence is rather small, consisting of a simple 1-1, 2-1-1,2 rhythm and the demand to move one finger after the other. On the other hand, interference in this task could be very strong, because a sequence of alternating commands concerns "semantically" closely related body parts, the finger of one hand.

The demonstration of a deficit in apraxia testing of Parkinson's disease patients that cannot be reduced to being a sequel of faulty execution resulting from akinesia, hypomotility, or tremor leads to the question whether basal ganglia damage of other origin might also have a deleterious effect on the central planning and control of intentional movements. Ideomotor apraxia with exclusively subcortical lesions of vascular origin is not frequent but has repeatedly been reported. ${ }^{29-31}$ Because of the anatomy of vascular supply, however, ischaemic lesions most oftenly encroach upon cortical as well as subcortical regions. Purely cortical lesions of the left parietal lobe following surgical excision lead only to a mild impairment in copying of complex arm movements that is distinctly less severe than ideomotor apraxia caused by stroke. $^{32}$ Kertesz and Ferro ${ }^{31}$ looked for patients who had moderate to severe apraxia as a sequel of stroke and in whom CT displayed only small lesions. They found that seven out of nine had subcortical frontal lobe lesions. Lesions in this location may lead to apraxia because they damage both the white matter connecting the occipital with the frontal lobes and the anterior callosal fibres connecting the premotor areas of both hemispheres. They are, however, very likely to encroach upon the anterior basal ganglia as well. The effects of basal ganglia damage may thus contribute to the clinical picture of ideomotor apraxia in patients with more extensive left brain damage.

We thank R Wytek for statistical advice. Calculations were performed at the Computing center of the University of Vienna, using the SPSS.

\section{References}

${ }^{1}$ Geschwind N, Damasio AR. Apraxia. In: Frederiks JAM ed. Handbook of Clinical Neurology, Vol 1 (49). Clinical neuropsychology. Amsterdam, New York. Elsevier 1985:423-32.

${ }^{2}$ Shape MH, Cermak SA, Say DS. Motor planning in Parkinson patients. Neuropsychologia 1983;21:455-62.

${ }^{3}$ Poeck K. The two types of motor apraxia. Arch.Ital Biol 1982;120:361-9.

${ }^{4}$ Flowers K. Visual "closed-loop" and "open-loop" characteristics of voluntary movement in patients with Parkinsonism and intention tremor. Brain 1976;99:268-310.

${ }^{5}$ Marsden CD. Function of the basal ganglia as revealed by cognitive and motor disorders in Parkinson's disease. Can J Neurol Sci 1984;11:129-35.

${ }^{6}$ Stern Y. Behavior and the basal ganglia. In: Mayeux $\mathbf{R}$, Rosen WG, eds. The Dementias. New York: Raven 1983:195-209.

${ }^{7}$ Birkmayer W, Neumayer E. Die moderne medikamentöse Behandlung des Parkinsonismus. Z Neurol 1972;202: 257-80.

${ }^{8}$ Birkmayer W, Riederer P. Parkinson's Disease. New York: Springer 1983.

${ }^{9}$ Hoehn MM, Yahr MD. Parkinsonism: onset, progression and mortality. Neurology 1967;17:427-42.

${ }^{10}$ Kaplan E, Goodglass H, Weintraub S, Segal O. Boston Naming Test. Philadelphia, Lea \& Febinger 1983.

${ }^{11}$ Piotrowski Z. The Rorschach inkblot method in organic disturbances of the central nervous system. J Nerv Ment Dis 1937;86:525-37. 
${ }^{12}$ Benton AL, Hamsher $\mathrm{K}$ de S, Varney NR, Spreen $\mathrm{O}$. Contributions to Neuropsychological Assessments. New York: Oxford University Press 1983.

${ }^{13}$ Radcliff G. Spatial thought, mental rotation and the right cerebral hemisphere. Neuropsychologia 1979;17:49-54.

${ }^{14}$ Luria AR. Higher Cortical Functions in Man. New York: Basic Books 1980.

${ }^{15} \mathrm{Kolb}$ B, Milner B. Performance of complex arm and facial movements after focal brain lesions. Neuropsychologia 1981;19:491-503.

${ }^{16}$ Boller F, Passafiume D, Keele NG, Rogers K, Morrow L, Kim Y. Visuospatial impairment in Parkinson's disease. Arch Neurol 1984;41:485-90.

${ }^{17}$ Mayeux R, Stern Y. Intellectual dysfunction and dementia in Parkinson disease. In: Mayeux R, Rosen WG eds. The Dementias. New York, Raven Press 1983:211-27.

${ }^{18}$ Mortimer JA, Firozzolo FJ, Hansch EC, Webster DW. Relationship of motor symptoms to intellectual deficits in Parkinson disease. Neurology 1982;32:133-7.

${ }^{19}$ Mortimer JA, Kuskowski HA, Webster DD. Parallel changes in cognitive and motor function in Parkinson's disease. Paper presented at 7th European INSconference, Aachen 1984.

${ }^{20}$ Hore J, Mayer Lohmann J, Brooks VA. Basal ganglia cooling disables learned arm movement of monkeys in the absence of visual guidance. Science 1977;195:584-6.

${ }^{21}$ Storandt M, Botwinick J, Danzinger WL, Berg L, Hughues CP. Psychometric differentiation of mild senile dementia of the Alzheimer type. Arch Neurol 1984;41:497-9.

${ }^{23}$ Goldberg G. Response and projection: a reinterpretation of the promotor concept. In: Roy EA ed. Neuro- psychological Studies of Apraxia and Related Disorders. Amsterdam, New York, Oxford: North Holland 1985:251-266.

${ }^{24}$ Cools AR, Bercken JHL, Horstink HWI, Spaendonck KPH van, Berger HNC. Cognitive and motor shifting aptitude disorder in Parkinson's disease. $J$ Neurol Neurosurg Psychiatry 1984;47:443-53.

${ }^{25}$ Lees J, Smith E. Cognitive deficits in the early stages of Parkinson's disease. Brain 1983;106:257-70.

${ }^{26}$ Proctor F, Riklan M, Cooper S, Teuber HL. Judgement of visual and postural vertical by Parkinsonian patients. Neurology 1964;14:287-93.

${ }^{27}$ Pribram KH, Tubbs WE. Short-term memory, parsing and the primate frontal cortex. Science 1967;156: 1756-7.

${ }^{28}$ Volpe BT, Hirst W. Amnesia following the rupture and repair of an anterior communicating artery aneurism. J Neurol Neurosurg Psychiatry 1983;46:704-9.

${ }^{29}$ Smyth MM. Memory for movements. In: Smyth MM, Wing AM ed. The Psychology of Human Movement. London. Academic Press 1984:83-118.

${ }^{30}$ Basso A, Faglioni P, Luzzatti C. Methods in neuroanatomical research and an experimental study of limb apraxia. In: Roy EA ed. Neuropsychological Studies of Apraxia and Related Disorders. North Holland 1985: 179-202. Amsterdam, New York, London.

${ }^{31}$ Kertesz A, Ferro JM. Lesion size and location in ideomotor apraxia. Brain 1984;107:921-33.

${ }^{32} \mathrm{Kolb} \mathrm{B}$, Whishaw IQ. Can the study of praxis in animals aid the study of apraxia of humans? In: Roy EA ed. Neuropsychological Studies of Apraxia and Related Disorders. Amsterdam, North Holland 1985:203-24. 